Session 2577

\title{
ABET 2000 and the Re-Engineering of Nuclear Engineering Departments
}

\author{
James S. Tulenko, Edward T. Dugan, David E. Hintenlang \\ Department of Nuclear and Radiological Engineering \\ University of Florida
}

\begin{abstract}
ABET Engineering Criteria 2000 emphasizes continuous improvement and professional preparation while offering flexibility for major innovations in curriculum design. The changes being seen in the nuclear engineering profession represent just the type of environment that ABET 2000 is particularly designed to help. ABET 2000 forces a continual assessment and feedback to ensure that current educational curriculum and processes are appropriate to our students' needs. The University of Florida has engineered its curriculum to meet the needs of its students in the current professional environment and has found ABET 2000 to be a positive factor in encouraging and abetting that re-engineering.
\end{abstract}

\section{INTRODUCTION}

A question often asked of the American Nuclear Society's Engineering Accreditation Commissioners (EAC) on the Engineering Accreditation Commission of the Accreditation Board of Engineering and Technology (ABET) by nuclear department heads is: "What will the effect of the new set of accreditation criteria (ABET Engineering Criteria 2000) have on the ongoing reengineering of nuclear engineering programs?" Nuclear engineering programs are currently undergoing a major change of life as the nuclear industry passes from a growing, building, power generation dominated phase into a steady power operation phase and a growing service/support industry. As nuclear engineering programs change to adjust to the changing employment/practice environment, they wonder if their new programs will still meet ABET/EAC engineering accreditation requirements. I have good news. ABET Engineering Criteria 2000 was created to "assure that graduates of an accredited program are adequately prepared to enter and continue the practice of engineering."1 This is exactly what we are trying to do with the ongoing re-engineering of nuclear engineering departments and programs.

\section{ABET ENGINEERING CRITERIA 2000}

ABET Engineering Criteria 2000 has been designed to focus on the needs of the educational progress of various constituencies. The crux of the new accreditation process is an ongoing evaluation (assessment) program that demonstrates achievement of these objectives and that uses the results of the assessment program to improve the effectiveness of the education program. To quote from ABET Engineering Criteria 2000,

"Engineering programs must demonstrate that their graduates have

(a) an ability to apply knowledge of mathematics, science, and engineering; 
(b) an ability to design and conduct experiments, as well as to analyze and interpret data;

(c) an ability to design a system, component, or process to meet desired needs;

(d) an ability to function on multi-disciplinary terms;

(e) an ability to identify, formulate, and solve engineering problems;

(f) an understanding of professional and ethical responsibility;

(g) an ability to communicate effectively;

(h) the broad education necessary to understand the impact of engineering solutions in a global/societal context;

(I) a recognition of the need for an ability to engage in life-long learning;

(j) a knowledge of contemporary issues; and

(k) an ability to use the techniques, skills, and modern engineering tools necessary for engineering practice."

The accreditation criteria provide a framework for nuclear engineering and radiological programs to design their curriculum to meet the professional needs of their students and to present an exciting challenge to attract students.

One has only to look at the decreasing enrollments nationally and the closing of nuclear engineering departments to realize that to continue to be successful, nuclear departments must develop strategic plans that define successful objectives in the educational process along with programs to assess how we are doing with continual adjustments. Over the last few years we have seen the University of Arizona, Kansas State University, Iowa State University, and Georgia Institute of Technology close their nuclear engineering departments and merge them into mechanical engineering departments. Most recently, the Pennsylvania State University, one of the flagship nuclear engineering undergraduate programs, announced that the nuclear department will become part of the mechanical engineering department. During the next few years, it is anticipated that approximately one-third of the current programs offering a nuclear engineering degree will be closed down. ABET 2000 requires that the nuclear engineering programs assess the productivity of their curriculums and make the changes necessary for a successful program.

Engineering technology is evolving to an atomic or nuclear basis. Engineers needs to know where every atom is and how to work on an atomic/nuclear level. Nuclear energy will be a key part of the future of this country and the world. The reduction in the number of nuclear engineering programs offers outstanding opportunities to those programs that adapt to the new environment and ABET 2000 will help to focus that adaption process.

\section{THE CHALLENGE}

The professional component of the ABET Engineering Criteria 2000 specifies "subject area(s) appropriate to engineering but do(es) not present specific courses . . . The curriculum must prepare student for engineering practice ...."Within the guidelines our task as nuclear engineering education professionals is to re-engineer the nuclear and radiological curriculum to ensure that we present the curriculum that meets the educational needs and opportunities in the nuclear field. Preparing our students to succeed in today's nuclear and radiological field is a 
challenge and an opportunity. We must re-think our curriculum to determine which skills are appropriate for our students to learn to be successful in their careers. The ABET Engineering Criteria 2000 could not have been better designed for nuclear engineering education at this time in its life cycle. The criteria forces us to ensure that we get the feedback from our students, prospective employers, national educational measurements, and professional advisory boards, to ensure that we are satisfying the needs of all constituents with our re-engineering and also that we are using the feedback to make our programs even better.

ABET Engineering Criteria 2000 ensures that we are incorporating those elements critical to the success of our graduates by its constant reassessment. If they are not successful we will get the feedback and incorporate its necessary changes. The criteria include a limited amount of required curricular content so that we can incorporate the necessary engineering coursework to make sure our students have the education to be successful in this new environment. The specific nuclear and radiological criteria have been kept simple, as follows:

"Graduates of the program should demonstrate the ability to apply advanced mathematics, science and engineering sciences, including atomic and nuclear physics, and the transport and interaction with matter, to nuclear and radiological systems and processes. Graduates should demonstrate the ability to work professionally in one or more of the nuclear or radiological fields of specialization identified by the program."

Following the ABET Engineering Criteria 2000, we at the University of Florida, have redesigned our curriculum to meet our end objective of preparing our students for useful, satisfying and productive careers in the nuclear field. The heavy reliance on nuclear power reactor systems and design courses have been replaced by an understanding of radiation, its transport and interaction, and an understanding of systems design in general. Our product is a nuclear engineering education, our customers are our students, their future employers, and our state and national needs. Feedback from students, employers, and the marketplace will alter or reinforce the direction we have taken. Our revised nuclear engineering curriculum is listed below along with the curriculum it replaced for reference. 


\section{CURRICULUM LEADING TO THE BACHELOR OF SCIENCE IN NUCLEAR AND RADIOLOGICAL ENGINEERING}

\section{$\underline{\text { New }}$}

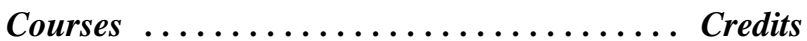

Pre-Engineering Curriculum $+\ldots \ldots \ldots \ldots \ldots 55$

STA 3032 Engr. Statistics ............... 3

CGC 3422 Computer Prog. For Engr. ........... 2 or CIS 3020 IntGGts G482(6)omputer Prog. For Engr.

ENC 2210 Technical Writing . . . . . . . . . . . . -

EMA 3010C Materials 1 .................. 3

PHY 3101 Modern Physics ................ 3

EEL 3111 Circuits $1 \ldots \ldots \ldots \ldots \ldots \ldots \ldots$

or EEL 3003 Elements of Elec. Engr (3)

EEL 3003L Elec. Circuits Lab . . . . . . . . . . . . . 1

ENU 4641 Applied Radiation Protection .......... 3

EML 3520 Analytic Methods in Mech. Engr. ...... 3

or EGM 4313 EnfiGAh315-10iffEechatiosins (Wlaterials

EML 3100 Thermo 1 ................... 3

ENU 4103 Intro. to Nuclear Engr $1 \ldots \ldots \ldots \ldots . \ldots 3$

ENU 4054 Rad. Transport \& Engr. Appl. $1 \ldots \ldots \ldots 2$

ENU 4055 Rad. Transport \& Engr. Appl. 2 . . . . . . 2

ENU 4621 Appl. of Radiation to Bio-Systems ..... 3

ENU 4145 Risk Assess. For Radiation Systems . . . . 3

ENU 4505L Nucl. Engr. Lab. 1 . . . . . . . . . . . . 2

ENU 4192 Nucl. \& Radiat. Engr. Design. . . . . . . . . 4

ENU 4605 Radiat. Interact. \& Sources 1 . . . . . . . . 2

ENU 4606 Radiat. Interact. \& Sources 2 . . . . . . . 2

ENU 4612 Radiat. Detect. \& Instrument .......... 3

ENU 4612L Radiat. Detect. \& Instrument Lab. . . . . . . 2

ENU 4934 Nuclear Engr. Seminar . . . . . . . . . . . 1

*Engr. Specialty Area Electives . . . . . . . . . . . . . 6

**Engr. Science, Design, or Tech. Electives ...... 9 ENU 4612 Nuclear Instrumentation Systems 1

Total CreditERkq4⿴囗3 Nuclear Engineering \$eßninar Engr. Science, Design, or Tech. Electives

\section{$\underline{\text { Previous }}$}

Courses ....................... Credits

Pre-Engineering Curriculum ............. 55

Note: This program requires $\mathrm{CHM}$

2046/2046L general chemistry . . . . . . . . . . . . .

2

ENC 3250 Professional Communication ............

EMA 3010 Materials $1 \ldots \ldots \ldots \ldots \ldots \ldots \ldots$

PHY 3101 Modern Physics . . . . . . . . . . . . . 3

EEL 3111 Circuits $1 \ldots \ldots \ldots \ldots \ldots \ldots \ldots$

or EEL 3003 Elements of Elec. Engr. (3)

and EEL 3368 Elec. Sys. \& Intstr.(2)

EEL 3303L Elec. Circuits Lab. . . . . . . . . . . . . . 1

EGM 3511 Engineering Mechanics-Statics. . ...... 3

3

ENV 4241 Fundamentals of Radiation Protect. . . . . . . 2

ENU 4001 Intro. to Nucl. Engr.Anal. 1 . . . . . . . . 3

ENU 4003 Intro. To Nucl. Engr. Anal. $2 \ldots \ldots \ldots \ldots$.

EML 3100 Thermodynamics $1 \ldots \ldots \ldots \ldots \ldots$

ENU 4103 Nuclear Engineering $1 \ldots \ldots \ldots \ldots \ldots$

ENU 4104 Nuclear Engineering $2 \ldots \ldots \ldots \ldots \ldots$

ENU 4144 Nuclear Power Reactor Systems 1 . . . . . . . 3

ENU 4145 Nuclear Reactor Safety \& Risk Anal. .... . . 3

ENU 4505L Nucl. Engr. Lab. $1 \ldots \ldots \ldots \ldots \ldots \ldots 2$

ENU 4134 Thermodynamics Heat \& Mass Transfer

in Nuclear Systems ................... 4

ENU 4192 Nucl. Reactor Power Plant Design 1 . . . . . 4

ENU 4194 Control of Nuclear Reactors and

Power Plants ..................... 3

ENU 4605 Interact. of Radiation with Matter ....... 3

3 ENU 4612L Nuclear Instrumentation Syst. Lab

1

$\underline{9}$

Total Credits Required

126

+3 credit Biological Sciences course replaces CHM 2046/2046L 
Our department is optimistic that this new curriculum will outfit our students to find productive careers. The new ABET Criteria 2000 has made this re-engineering even easier than it would have been under previous accreditation criteria because it forces us to continually validate our education preparation against the needs of the marketplace and our students..

\section{CONCLUSION}

We at the University of Florida are confident that the employment and research opportunities are there for our students to have productive and successful careers in nuclear and radiological engineering and that our new curriculum will best prepare our students to exploit to the maximum the opportunities available. The new ABET Engineering Criteria 2000 along with the program criteria developed by the Accreditation Committee of the American Nuclear Society have both supported and encouraged the re-engineering of our curriculum. Furthermore, the assessment focus of the new 2000 criteria ensures that we are measuring our own new curriculum to verify that it is meeting the needs of all involved in our educational process, students, employers, faculty, state, and nation. It requires that we make these measures and prevents us from burying our heads in the sand. ABET Engineering Criteria 2000 requires that we continually assess our program and respond in a positive and productive way. 


\section{Biographical Information}

JAMES S. TULENKO [BA, engineering physics, Harvard College, 1958; MA, engineering physics, Harvard University, 1960; MS, nuclear engineering, MIT, 1963; MEA, George Washington University, 1980] is professor and chairman of the Nuclear and Radiological Engineering Department, University of Florida. Research interests include nuclear fuel design and performance, fuel cycle analysis and management, radioactive waste management, and remote technologies including robotics.

EDWARD T. DUGAN is an associate professor and undergraduate advisor and curriculum committee chairman in Nuclear and Radiological Engineering, University of Florida. He received a B.S. in Mechanical Engineering from the University of Notre Dame and an M.S. and Ph.D. (1976) in Nuclear Engineering from the University of Florida. Research interests include reactor analysis, space nuclear power, reactor dynamics and control, and radiation transport.

DAVID E. HINTENLANG is an Associate Professor and coordinator for the graduate and undergraduate Health Physics Programs in Nuclear and Radiological Engineering, University of Florida. He received his Ph.D. in Physics from Brown University in 1985. Research interests include indoor radon, radiation dosimetry for medical procedures, development of methods to process radioactive wastes, and the application of radiation for nondestructive testing applications. 